\title{
Students' Pre-Initial Mental Model: The Case of Indonesian First-Year of College Students
}

\author{
Anita Dewi Utami \\ Dr. candidate of Mathematics Education, Graduate School, Universitas Negeri Malang, \\ East Java, Indonesia, anita.dewi.1603119@students.um.ac.id \\ Cholis Sa'dijah \\ Professor of Mathematics Education., corresponding author, Graduate School, \\ Universitas Negeri Malang, East Java, Indonesia, cholis.sadijah.fmipa@um.ac.id

\section{Subanji} \\ Assoc. Prof of Mathematics Education., Graduate School, Universitas Negeri Malang, \\ East Java, Indonesia, subanji.fmipa@um.ac.id

\section{Santi Irawati} \\ Assoc. Prof. of Mathematics, Graduate School, Universitas Negeri Malang, East Java, \\ Indonesia, santi.irawati.fmipa@um.ac.id
}
Mental models are one form of ideas in the minds of individuals that can be used to describe, explain and predict a particular phenomenon. The pre-initial form of individual mental models can be seen from information held by children stored in their long-term memory before they are confronted with a particular concept. The purpose of this study was to describe the characteristics of pre-initial mental models of first-grade students in understanding the concept of function. This study belongs to qualitative research with a case study design. The case that was observed in this study was the students' pre-initial mental model in understanding the concept of function. The researchers, then, set two subjects of each reason for the answers to be interviewed. To guarantee the validity and reliability of the research, the triangulation technique was employed by displaying the data yielded from the interview video and comparing it with the results of the students' written test. The results show that first-grade students who are at the level of pre-initial mental models do not understand the concept of relations well so that they are not able to solve the problem of relations that is not a function.

Keywords: mental model, student, function, understanding, college students 


\section{INTRODUCTION}

One of the interesting things in the process of learning mathematics is the way students construct concepts and connect one concept to another to build knowledge. When students want to build a concept by linking other concepts, there is a conceptual change in their mind. Research on conceptual change has been studied by several researchers (Stafylidou \& Vosniadou, 2004; Vosniadou \& Vamvakoussi, 2006; Vosniadou, 2007; Nadelson et al, 2018). Vosniadou (2007) argues that conceptual change is a new understanding of a person which is the result of a rational process as a substitute for a previously existing theory in one's mind. During the process of conceptual change (Stafylidou \& Vosniadou, 2004), students often develop conceptions as their attempt to incorporate new information into conceptual structures that provide insight into how they think about these concepts. Vosniadou and Vamvakoussi (2006) state that conceptual change is achieved when students experience dissatisfaction with existing ideas. Nadelson et al. (2018) state that the conceptual changes are the basis of learning science. Therefore, Science teachers need an effective learning model to investigate the students' conceptual changes.

Conceptual change is more likely to occur when students can experience a direct phenomenon in the classroom. The study by Sinatra, Brem and Evans (2008) suggest that conceptual change shows the level of involvement of students in content through discussion, debate, dialogue, or experimentation that allows the conceptual change in students. The simplest form of student conceptual change (Vosniadou, 1994) is the enrichment of existing conceptual structures. Enrichment is defined as simple additions of new information to theoretical frameworks. Conceptual change involves enriching or revising the student's conceptual structure to accommodate new knowledge. Revisions are necessary if the information which will be obtained does not conform to existing beliefs or presuppositions, or to the relational structure of the theory.

Important information about the student's understanding structure underlying from which the knowledge is generated can be known through the mental model (Vosniadou \& Brewer, 1992). Furthermore, Jansoon (2009) explains that the mental model is one form of ideas in the minds of individuals that can be used to describe, explain, and predict a particular phenomenon. Solaz-Portoles and Loppez (2007) describe that a mental model is used to explain the process of individual reasoning in solving the problem of syllogism. Senge (2004) also explains the mental model is an internal picture of how the world works, the image that limits one to thinking and acting. A person is often unaware to realize a person's mental model or the influence of a mental model on one's behavior.

Tasker and Dalton (2006) state that mental models as transformations of external representations into internal representations. The interaction between internal and external representations is the basis for effective teaching and learning. Whatever the meaning and interpretation of the teacher can bring to the external representation, it is the nature of developing an internal representation of the student that must remain a major concern. Furthermore, Buckley and Boulter (2007) explain that the mental model is an intrinsic representation of an idea or process that can be produced by an individual 
that can be used to present a reason, explain, describe, predict a phenomenon and can produce a model of expression in various formats. The formation of internal representations in the form of mental models (Solaz-Portoles \& Loppez, 2007) in working memory of the world and combining information stored in long-term memory with information available in the characteristics of this problem will be extracted by process perception in memory.

Research on the mental model of students on the understanding of the concept of negative integers has been investigated by Bofferding (2014). Bofferding (2014) found five mental models of students in understanding the concept of integers, the initial mental model, transition 1 , the synthetic mental model, the transition 2 , and the formal mental model. Utami et al. (2018) found one mental model beside these five mental models, namely the pre-initial mental model, the initial mental model, the transition 1 , the synthetic mental model, the transition 2, and the formal mental model. The form of the child's initial mental model can be seen from his assumption when they have not confronted any information from adults about a particular concept. As for the transitional mental model 1 can be seen from the efforts of children who have not perfect in reconciling his assumptions with information from adults about a particular concept. To form a synthetic mental model of the child can be seen from the individual's efforts in reconciling his assumptions with information from adults about a particular concept. While the form of a transitional mental model 2 can be seen when the child has not completely resolved their framework theory before they are faced to the new and wider concepts and accommodates new information to reflect an adult's understanding of a particular concept. Formal models of the child's mental model can be seen when they successfully reorganize their framework theories and accommodate new information to reflect an adult understanding of a particular concept.

The researchers intended to develop Bofferding's (2014) research on the concept of function, since the function is an important concept in mathematics (Laughbaum, 2003; Knuth, 2000; Mesa, 2004). In addition, there are still many students who get difficulties in understanding the representation of the function (Thomspson \& Sfard, 1994; Thompson, 1994; Gagatsis et al., 2004, Elia et al., 2006; Maharaj 2008). Research on the conception of students about the concept of function has been studied by several researchers such as Attorps (2006), Hansson (2006), Juter (2006), Pettersson (2008), Viholainen (2008) and Dubinsky \& Wilson (2013).

Some research on the concept of function that has been done by previous researchers, the researchers have not deepened about the level of students' mental model in understanding the concept of function. For that reason, it is necessary to research the students' mental model in understanding the concept of function that can be used to accommodate all levels of students' understanding of the function concept. Based on preliminary studies, the researchers found that before the students arrive at the initial mental model stage, students are still in the pre-initial stage of the mental model. The pre-initial mental model in understanding the concept of function can be seen when the student has not understood the concept of relation well and has not been able to state that a relation is not a function. This can be shown in Figure 1. 


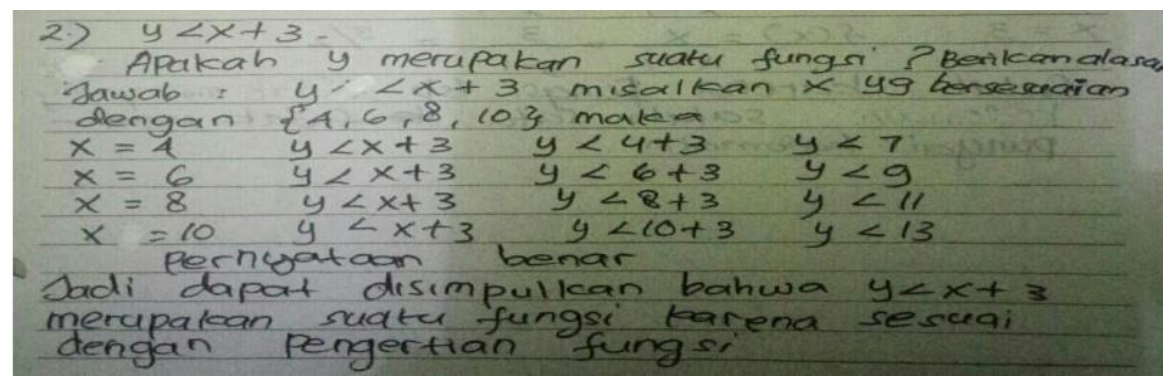

Figure 1

Student's Answer

(Question: $y<x+3$, is the ' $y$ ' a function? Give your reasons! Answer: $y<x+3$, if $x$

equals with $\{4,6,8,10\}$, so: $x=4 \quad y<x+3 \quad y<4+3 \quad y<7$

$$
x=10 \quad y<x+3 \quad y<10+3 \quad y<13
$$

The statement is true. So, it can be concluded that $y<x+3$ is a function because it is suitable with the concept of function)

The student's answer shows that $y<x+3$ is a function because it is in accordance with the meaning of the function. After the researchers asked what a function is based on his understanding, he answered the function is a special relationship. Further, the researchers asked what a relation is based on his understanding. He stated that it is the rules that connect the members of the set A to the set $\mathrm{B}$. Based on the results of student's answers and interviews, it appears that the student has not understood the concept of the 'relation' well, so he has not been able to solve problems about relation which is not function. Based on this preliminary study, the researchers assume that the student is at the level of the pre-initial mental model. The form of individual pre-initial mental models can be seen from information held by individuals stored in long-term memory before they are confronted with a particular concept. At this pre-initial level, before the individual is confronted with the concept of function, the individual's understanding of the relation is still imperfect.

When students are at the pre-initial level of mental models, it is difficult for them to understand the concept of function. This is because the pre-requisite material to learn the concept of function is the students must understand well the concept of relations. Therefore, it is needed to do further research on the truth of the researchers' assumption that whether there are still some students who are at the level of the pre-initial mental model in understanding the concept of function or not. If so, what are the characteristics of the student's mental model in understanding the concept of function?

\section{METHOD}

This study belongs to qualitative research with a case study design. The case that was observed in this study was the students' pre-initial mental model in understanding the concept of function. 


\section{Research Subject}

The subjects in this study were 48 first-grade students. All subjects were given test questions dealing with the relations that are functions and not functions. The subjects were asked to determine whether a relation in the question is a function or not, along with the reason for the answer. The subjects could identify the relations that are functions correctly. However, they could not identify the relations that are not functions. From the total answer of 48 students, there were 28 students who answered that the relations are not a function and 20 students who answered that the relations are functions.

This can be shown in Table 1.

Table 1

Classification of Student Answers

\begin{tabular}{lll}
\hline No. & Number of Students & Students' Answers \\
\hline 1. & 28 & The relations are not functions \\
\hline 2. & 20 & The relations are functions \\
\hline
\end{tabular}

Based on the answer of 20 students who answered that the relation is a function, there are three different reasons. This can be shown in Table 2.

Table 2

Reason for Student Answers

\begin{tabular}{lll}
\hline $\begin{array}{l}\text { No. } \\
\text { Students }\end{array}$ & $\begin{array}{l}\text { Number of } \\
\text { Reasons }\end{array}$ \\
\hline 2. & 2 & $\begin{array}{l}\text { The relation is a function because it is in accordance with the meaning } \\
\text { of the function. }\end{array}$ \\
& The relation is a function because of each domain $\mathrm{x}_{1}$ and $\mathrm{x}_{2}\left(x_{1} \neq x_{2}\right)$ \\
& so $x_{1} \neq x_{2}$ \\
\hline 3. & 14 & $\begin{array}{l}\text { The relation is a function because the set A (domain) has exactly one } \\
\text { pair with set B (codomain). }\end{array}$ \\
\hline
\end{tabular}

\section{Data collection}

The data in this study were collected through tests and interviews. The test questions include an understanding of the relation which is a function or a non-functional relation. All subjects were given test questions, and the subjects with certain criteria were selected for interviews. Criteria for the subjects chosen to be interviewed were those who did not yet understand the definition of a relation. This was because this study will discuss the characteristics of pre-initial mental models of students in understanding the concept of function. The pre-initial mental model of students in understanding the concept of function can be seen when the subject has not been able to understand a relation which is a function or not a function. After the researchers get the subject that has not understood the concept of relations, other criteria that researchers set was the communication skill of the research subjects. This needs to be done so that researchers can easily obtain the data from interviews. 


\section{Data analysis}

The process of data analysis in this study was done by the steps (Creswell, 2015): (1) transcoding the collected data, in this study, the data that were transcribed were the results of the test and interview with the subjects; (2) reviewing available data from test results and interview transcripts; (3) conducting data reduction by selecting, focusing and classifying similar data, then simplified by throwing away unnecessary things. The researchers selected the data yielded from the test which are suitable with the indicators that had been decided before, then they classified the results based on the level of students' pre-initial mental model in understanding the concept of function by simplifying and throwing away the unnecessary things; (4) presenting data of research result. In this step, the researchers presented the research results of the students' test which are in the level of pre-initial mental model and the results of interview to clarify their answers; (5) analyzing the process of formation of the students' pre-initial mental model in understanding the concept of function with the framework of the constructive mechanism of reflective-abstraction knowledge, (6) verifying the findings and drawing conclusions. In this step, the researchers verified the findings, in this case was the students' pre-initial mental model in understanding the concept of function, then they drew the conclusion for this research. This study was intended to investigate the students in constructing the knowledge in understanding the concept of function. In order to be able to investigate the way how the students construct their knowledge, the Piaget's framework is needed to analyse the collected data. Piaget (in Dubinsky, 2002) states that the development of cognitive structures is caused by reflective abstractions. To explain this theory and to associate concepts in mathematics, Dubinsky (2002) states that there are five constructions in a reflective abstraction, namely interiorization, coordination, reversal, encapsulation, and generalization. The construction definition in this study is presented in Table 3.

Table 3

Definition of Construction in Research

\begin{tabular}{ll}
\hline Construction Process & Definition of Construction \\
\hline Interiorization & $\begin{array}{l}\text { Thinking activity in digging the necessary information (e.g. domain } \\
\text { with a certain number). }\end{array}$ \\
\hline Coordination & $\begin{array}{l}\text { Constructing a new process from two or more other processes } \\
\text { (substituting the domain into the equation). }\end{array}$ \\
\hline Reversal & Construction reverses process (returns equation to inequality). \\
\hline Encapsulation & $\begin{array}{l}\text { Constructing mental objects from mental processes (depicting in the } \\
\text { form of arrow diagrams or Cartesian diagrams) }\end{array}$ \\
\hline Generalization & $\begin{array}{l}\text { Applying the scheme into a wider collection of phenomena (inferring } \\
\text { function or not function). }\end{array}$ \\
\hline
\end{tabular}

The researchers observed the activities of students who were completing the test questions provided. Furthermore, researchers conducted interviews with selected research subjects. The data in this study were obtained from the test of students after they solved the problem in understanding the concept of functions and interviews with the students conducted by the researchers. In this study, each interview in the video and the results of the written test of students were collected. To ensure the validity and 
reliability of the research, data analysis was performed by triangulation through the display of data from the video and comparing it with the students' written test data.

The interview video was analyzed by looking at the details of it and the students' written test results to determine the level of the pre-initial model of the student in understanding the function concept. After the categories of each characteristic of the mental-pre-initial model are determined, the next is to begin to process the data according to the characteristics of the pre-initial model of the student in understanding the concept of function. This categorization is an important step in data analysis because it facilitates meaningful data interpretation. This categorization comes through a literature review, identifying each interview answer and a student writing test that represents related concepts in the literature

\section{FINDINGS}

This study was about the level of mental model which was previously investigated by Bofferding (2014). Bofferding (2014) classified the level of students' mental model in understanding the concept of integer. In this study, the researchers developed Bofferding's (2014) study in the concept of function. The concept of function is an important concept that must be understood by students since it is one of the basic concepts in Mathematics.

\section{Research Result}

Here is an explanation of each answer that shows the level of the pre-initial model of the student in understanding the concept of function. The answer Subject 1 (S1) along with the description and explanation are shown in Figure 2 below.

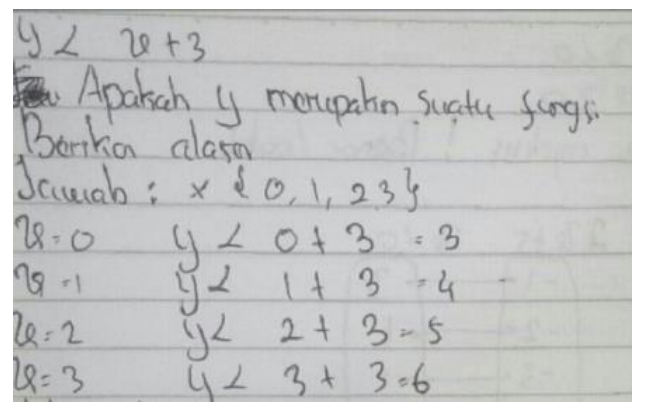

[y<x+3, is ' $y$ ' a function? Give your reason!

Answer; $x\{0,1,2,3\}$

$$
\begin{array}{lc}
x=0 & y<0+3=3 \\
\ldots \ldots \ldots \ldots \ldots \ldots \ldots \ldots \ldots \ldots \ldots \ldots \ldots \ldots \ldots \ldots & \ldots \ldots \ldots
\end{array}
$$

Figure 2

Part 1 of S1's answer 
S1 exemplified the domain with numbers $0,1,2$, and 3 without giving a reason why he exemplified with those numbers. Then he substituted the domain member into the inequality, but mixed the inequality with the equation sign and ignored the sign of inequality < (less than). S1 has done the process of interiorization that he tried to dig the information in the problem by writing the domain $\mathrm{x}$ with numbers $0,1,2$, and 3 . Although S1 has not successfully interiorized the problem correctly, he still tried to continue the process of coordination by substituting the value of $\mathrm{x}$ into the inequality

$<x+3$.

After S1 tried to interiorize and coordinate the problem, he attempted to encapsulate the problem by describing it in the arrow diagram (assuming the above inequality as the equation). This can be shown in Figure 3 below.

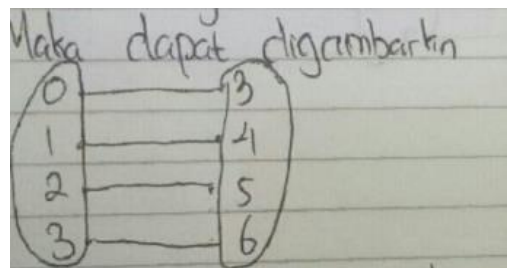

[so, it can be drawn:.....

Figure 3

Part 2 of S1's answer

$\mathrm{S} 1$ seems to illustrate the equation of image 1 into the arrow diagram without

considering the initial problem i.e. $y<x+3$. After the researchers asked why he described it as such, he simply replied that the domain substitution results in Figure 1 can be represented by the arrow diagram. Based on the result of image 2 made by S1,

then he tried to generalize by concluding that $y<x+3$ is a function because it is in accordance with the meaning of the function. This can be shown in Figure 4 below.

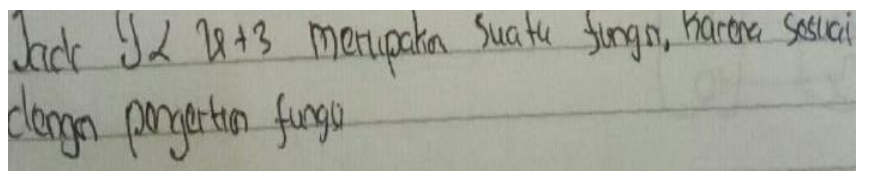

[so, $y<x+3$ is a function, because it is in line with the concept of function]

Figure 4

Part 3 of S1's answer

After the researchers asked what the function is based on his understanding, he answered the function is a special relationship. Further, the researchers asked what the relation is based on his understanding. S1 answered that it is the rules that connect members of set A to set B. 
Differ from the S1, subject 2 (S2) seemed unsure of writing down the answer. This can be seen when he has completely written the inequality and then he exemplified the domain with the variables $\mathrm{x}$ and $\mathrm{y}$, then he re-wrote the inequality and tried to substitute $\mathrm{x}$ on the inequality $y<x+3$. This can be seen in Figure 5 below.

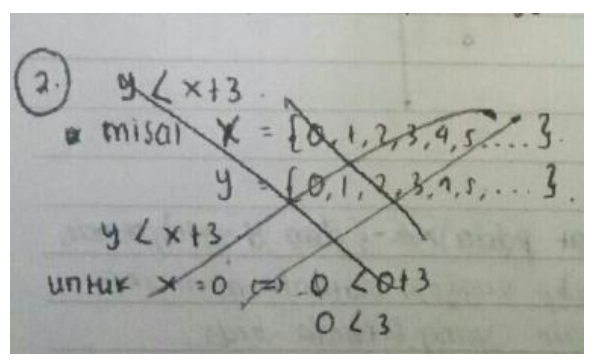

Figure 5

Part 1 of S2's answer

When the researchers asked why he had changed the answer (by putting the cross on the answer), he replied that he was still in doubt. After deleting some of his writings, he

tried to interiorize it by rewriting the inequality of $y<x+3$ and exemplified $x$ to the numbers 0,1 , and 2 . Then he attempted to coordinate the problem structure by

substituting the numbers 0,1 and 2 into inequality $y<x+3$ and got the conclusion $(0,3) ;(1,4) ;(2,5)$. This can be shown in Figure 6 below.

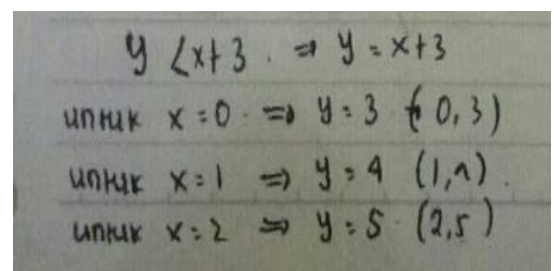

Figure 6

Part 2 of S2's answer

S2 began to encapsulate by describing it in the Cartesian graph of the dots that it generates from the substitution of the value of $\mathrm{x}$ into the inequality $y<x+3$. This can be seen in Figure 7 below. 


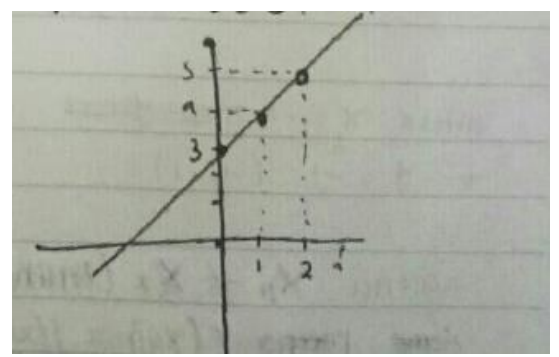

Figure 7

Part 3 of S2's answer

He succeeded in drawing a straight line on the inequality Cartesian graph of the equation $y=x+3 \quad$ (he did not think if the initial question is not the equation but the inequality). After he knew that the graph he described from the substitution of $x$ and $y$ is a straight line, he tried to generalize by concluding that $y<x+3$ is a function because of the domains $x_{1}$ and $x_{2}$ with $\left(x_{1} \neq x_{2}\right)$, so, $x_{1} \neq x_{2}$. This can be shown in Figure 8 below.

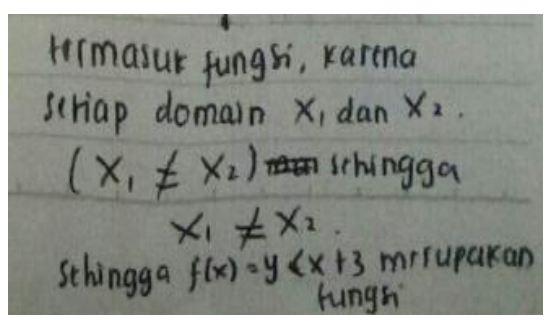

[it belongs to function, because every domain $x_{1}$ and $x_{2}\left(x_{1} \neq x_{2}\right)$, so $\left(x_{1} \neq x_{2}\right)$, so

$f(x)=y<x+3$ is a function]

Figure 8

Part 4 of S2's answer

S2 concluded that $y<x+3$ is a function because every domain $x_{1}$ and $x_{2}\left(x_{1} \neq x_{2}\right.$.),

so $x_{1} \neq x_{2}$ then $f(x)$ is a function. After the researchers asked what the function is based on his understanding, S2 replied that the relation is the relationship between the set.

In contrast to the $\mathrm{S} 2$ who seemingly unsure by crossing his answer, subject 3 (S3) seemed sure to write his answers nicely and neatly. S3 started the interiorization process by providing $\mathrm{x}$ with $-1,0$, and 1 . This can be shown in Figure 9 below. 


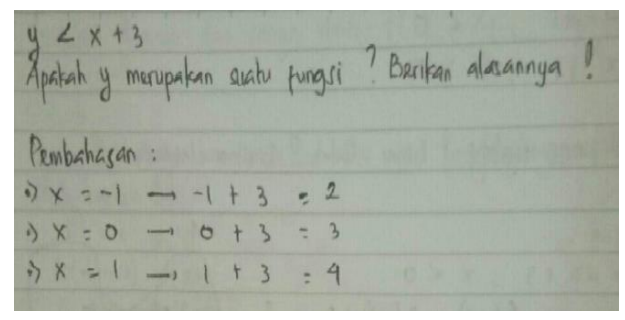

[y $<x+3$, is y a function? Discussion:

Figure 9

Part 1 of S3's answer

After S3 has provided $\mathrm{x}$ with $-1,0$, and 1 , then he tried to coordinate each element of the domain by substituting the $\mathrm{x}$ into the equation $y=x+3$ (regardless of the question command is the inequality $y<x+3$. After obtaining the results of the substitution, he started to encapsulate by depicting it in the arrow diagram. This can be shown in Figure 10 below.

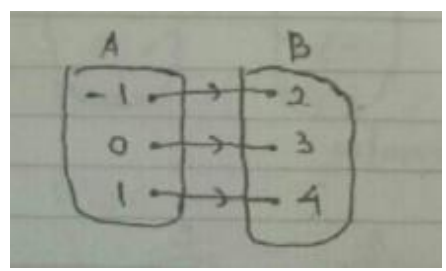

Figure 10

Part 2 of S3's answer

After S3 illustrated the results in the arrow diagram and he thought that $y<x+3$ can be represented in the arrow diagram, then he made generalizations by making the final conclusion that $y<x+3$ is a function because all sets A (domain) are paired exactly one with the set B (codomain). This can be shown in Figure 11 below.

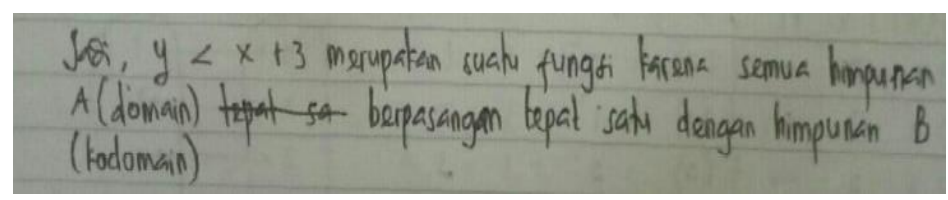

[so, $y<x+3$ is a function because each member of the association A (domain) has its partner with association $B$ (co-domain)]

Figure 11

Part 3 of S3's answer 
After the researchers asked what the function is based on his understanding, S3 answered that he only memorized it. For that, the researchers, further, asked what he knew about the relation. S3 answered that the relation is a rule that connects members of set A to set B.

\section{DISCUSSION}

The results of Vosniadou \& Brewer (1992) study suggest that there are three levels of mental models of students in understanding the concept of Earth form, namely the initial mental model, the synthetic mental model, and the formal mental model. Bofferding (2014) developed the mental model level of Vosniadou (1992) from three levels to five levels of mental models in understanding the concept of integers by adding a transitional level 1 mental model between the level of the initial mental model and the synthetic mental model and inserting the transitional mental model level 2 between the level of synthetic mental models and formal mental models. The initial mental model of students in understanding the concept of integers can be seen when students perceive the value of negative numbers as well as positive numbers (students assume numbers to the left of zero as well as positive integers). In fact, the researchers found that there are students who still do not understand the number on the left of one is the zero number. The researchers classified the student at the level of the pre-initial model. The pre-initial form of the child's mental model can be seen from information held by children stored in long-term memory before they are confronted with a particular concept.

At the elementary school level, the material of numbers is very essential. While at the college level, one of the essential materials is the function. The students-teachers of mathematics should have the ability to understand a concept. Moreover, the concept of the function which is one of the essential concepts in mathematics since it underlies other mathematical concepts. In addition, the function is also an important concept in mathematics (Laughbaum, 2003; Knuth, 2000; Mesa, 2004). The prerequisite for understanding the concept of function is that students must understand the concept of relations. In fact, this present study shows that there were some students who still did not understand the concept of relations so that they are not able to solve the problem of the relation is a function or not a function.

Based on the results of the study, students who were still at the level of pre-initial mental models had tried to do the process of interiorization by digging the information from the problem. Students at the pre-initial mental model level interfere with the problem structure faced on a relation problem which is not a function by assigning a domain to a particular number without giving the reason for sampling the number taken for the domain. After the process of interiorization, students continued on the process of coordination by substituting the domain into the inequality that has been converted into an equation.

In the next stage, the students did not do the reversal process. Reversal is a process to change the equation into an inequality in accordance with the instruction. But, they continued on the process of encapsulation by representing the arrow diagram and Cartesian diagram. The representation of functions in the form of graphs or diagram 
created by the students led them to misunderstand the concept of function. This is in accordance with Dede and Soybas (2011) who state that the representation of functions with graphics can result in students' misunderstanding of the concept of function. After creating the function graph, the students then proceeded on the generalization process by concluding that the relation in question is a function. The above process can be seen in Figure 12 below.

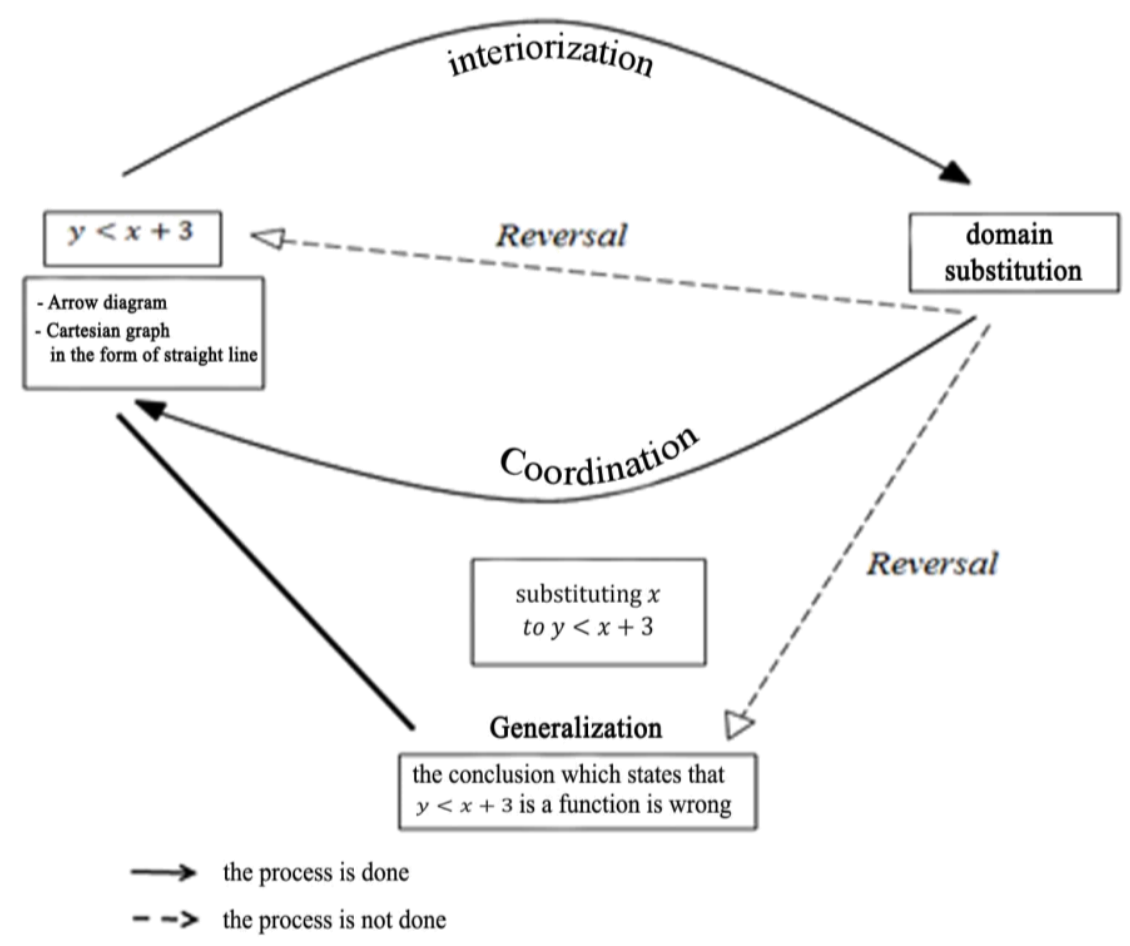

Figure 12

Construction Mechanism of Function Concept

(Adopted from the Meel Knowledge Construction Mechanism Scheme, 2003)

Based on the process of knowledge construction through the mechanism of reflective abstraction, the characteristics of students who are at the level of pre-initial mental models are as follows. The subject defines the domain with a certain number without giving the reason for sampling the number taken to be the domain. The subject substitutes the domain into the inequality and converts into the equation. The subject does not pay attention to the sign < (less than) as an inequality. Subject mixes inequalities with an equal sign. The subject represents the inequality of the Cartesian graphs and produces a straight line. The subject represents inequalities with arrow 
diagrams. The subject makes the final conclusion of the drawing made without reviewing whether the image he created is an image which reflects inequality.

\section{CONCLUSION}

Based on the research findings of the pre-initial mental model of the first-grade students, it is concluded that pre-initial mental model can be seen from information held by students stored in long-term memory before they are confronted with a particular concept. It can be seen that the student has not understood the concept of relation so that he is not able to solve the problem about the relation which is a function or not a function. The characteristics of mental models of students in understanding the concept of function are they declare the relation as a rule that connects members of set $\mathrm{A}$ to the set $\mathrm{B}$ and state that the relation is the relationship between the set.

The researchers recommend further research, so that, it can explore more deeply whether the level of other mental models is also possible to be developed. This is due to before the initial mental model there is a level that precedes it, i.e. the level of pre-initial mental models.

\section{REFERENCES}

Attorps, I. (2006). Mathematics teachers' conceptions about equations. Doctoral dissertation. Department of Applied Sciences of Education, University of Helsinki.

Bofferding, L. (2014). Negative integer understanding: characterizing first graders' mental models. Journal for Research in Mathematics Education, 45(2), 194-245.

Buckley, B. C. \& Boulter, C., J. (2007). Investigating the role of representations and expressed model in building mental models. In J. K. Gilbert and C. J. Boulter (Eds.), Developing Models In Science Education (119-135). Netherlands: Kluwer Academic Publishers.

Creswell, J. W. (2015). Qualitative research and research design: choosing from five approaches. Yogyakarta: Pustaka Belajar.

Dede, Y. \& Soybas D. (2011). Preservice mathematics teachers' experiences about function and equation concepts. Eurasia Journal of Mathematics, Science and Technology Education, 7(2), 89-102.

Dubinsky, E. (2002). Genetic decompositions of three schemas. Cited in D.Tall (Ed.), Advanced Mathematical Thinking (pp. 109-116). New York: Kluwer Academic Publisher.

Dubinsky, E. \& Wilson, R.T. (2013). High school students' understanding of the function concept, The Journal of Mathematical Behavior, 32(3), 83-101.

Elia, I., Panaoura A., Eracleous A., \& Gagatsis A. (2006). Relations between secondary pupils' conceptions about functions and problem solving in different representations, International Journal of Science and Mathematics Education, 5(1), 533-556. 
Gagatsis, A. \& Shiaklli, M. (2004). Ability to translate from one representation of the concept of function to another and Mathematical problem solving, Educational Psychology, 24(5), 645-657.

Hansson, Ö. (2006). Studying the views of preservice teachers on the concept of function. Doctoral dissertation. Department of Mathematics, Luleå University of Technology.

Jansoon, N. (2009). Understanding mental models of dilution in Thai students. International Journal of Environmental \& Science Education. 4(2), 147 - 168.

Juter, K. (2006). Limits of functions: University students' concept development. Doctoral dissertation. Department of Mathematics, Luleå University of Technology.

Knuth, E. (2000).Understanding connections between equations and graphs. The Mathematics Teacher, 93(1), 48-53.

Laughbaum, E. (2003). Developmental algebra with function as the underlying theme. Mathematics and computer education 37(1), 63-71.

Maharaj, A. (2008). Some insights from research literature for teaching and learning mathematics. South African Journal of Education, 28(3), 401-414.

Meel, D. E. (2003). Models and theories of Mathematical understanding: Comparing Pirie and Kieren's model of the growth of Mathematical understanding and APOS theory. CBMS Issues in Mathematics Education, 12(2), 132-181.

Mesa, V. (2004). Characterizing practices associated with functions in middle school textbooks: An empirical approach. Educational Studies in Mathematics. 56 (2), 255286.

Nadelson, L. S., Heddy, B. C., Jones, S., Taasoobshirazi, G., \& Johnson, M. (2018). Conceptual change in Science teaching and learning: Introducing the dynamic model of conceptual change. International Journal of Educational Psychology, 7(2), 151-195. doi:10.17583/ijep.2018.3349

Pettersson, K. (2008). Algoritmiska, intuitiva och formella aspekter av matematiken Idynamiskt samspel. En studie av hur studenter nyttjar sina begreppsuppfattningar inom matematisk analys. [Algorithmic, intuitive and formal aspects of mathematics in dynamic interplay: A study of students' use of their conceptions in calculus.] Doctoral dissertation. Department of Mathematical Sciences, University of Gothenburg.

Senge, P. M. (2004). The fifth discipline. the art and practice of the learning organization. New York: Doubleday Dell Publishing Group, Inc. 405 pages.

Sinatra, G. M., Brem, S. K.., \& Evans, E. M. (2008). Changing Minds? Implications of conceptual change for teaching and learning about Biological evolution. Evo Edu Outreach, 1:189-195 DOI 10.1007/s12052-008-0037-8. 
Solaz-Portolẻs, J. J. \& Lopez, V.S. (2007). Representations in problem-solving in science: Directions for practice. Asia-Pacific Forum on Science Learning and Teaching, 8 (2). Article 4 (December 2007).

Stafylidou, S. \& Vosniadou, S. (2004). The development of students' understanding of the numerical value of fractions. Learning and Instruction, 14(5), 503-518.

Tasker, R. \& Dalton, R. (2006). Research into Practice: visualization of the molecular world using animations. Chem. Educ. Res. Prac, 7(2), 141-159.

Thompson, P. W. (1994). Students, functions, and the undergraduate curriculum. In E. Dubinsky, A.H. Schoenfeld, \& J. Kaput (Eds.), Research incollegiate mathematics education. I: (21-44). Providence, RI: American Mathematical Society.

Thompson, P. W. \& Sfard, A. (1994). Problems of reification: Representations and Mathematical objects. In D. Kirshner (Ed.) Proceedings of the Annual Meeting of the International Group for the Psychology of Mathematics Education-North America, Plenary Sessions 1: (pp. 1- 32). Baton Rouge, LA: Lousiana State University.

Utami, A. D., Sa'dijah, C., Subanji, \& Irawati, S. (2018). Six levels of Indonesian primary school students' mental model in comprehending the concept of integer. $\begin{array}{llll}\text { International Journal of Instruction, } & \text { 11(4), }\end{array}$ https://doi.org/10.12973/iji.2018.1143a

Viholainen, A. (2008). Prospective mathematics teachers' informal and formal reasoning about the concepts of derivative and differentiability. Doctoral dissertation. Department of Mathematics and Statistics, University of Jyväskylä.Vosniadou, S., \& Brewer, W. F. (1992). Mental models of the earth: A study of conceptual change in childhood. Cognitive Psychology, 24(4), 535-585.

Vosniadou, S. (2007). Conceptual change and education. Human Development, 50:4754 DOI: $10.1159 / 000097684$.

Vosniadou, S. (1994). Capturing and modeling the process of conceptual change. Learning and Instruction, 4(1), 45-69. doi:10.1016/0959-4752(94)90018-3.

Vosniadou, S. \& Brewer, W. F. (1992). Mental models of the earth: A study of conceptual change in childhood. Cognitive Psychology, 24(4), 535-585.

Vosniadou, S. \& Vamvakoussi, X. (2006). Examining Mathematics learning from a conceptual change point of view: Implications for the design of learning environments, Instructional Psychology: Past, Present, and Future Trends: Sixteen Essays in honour of Erik De Conte Copyright (C) 2006 by Elsevier Ltd. Pp:55-70. 